\title{
Outer membrane porin M35 of Moraxella catarrhalis mediates susceptibility to aminopenicillins Marion Jetter ${ }^{1}$, Nadja Heiniger ${ }^{2}$, Violeta Spaniol ${ }^{1}$, Rolf Troller ${ }^{1}$, André Schaller ${ }^{3}$ and Christoph Aebi*1,4
}

Address: ${ }^{1}$ Institute for Infectious Diseases, University of Bern, CH-3010 Bern, Switzerland, ${ }^{2}$ Division of Infectious Diseases, University of California at San Francisco, USA, ${ }^{3}$ Division of Human Molecular Genetics, University of Bern, Inselspital, CH-3010 Bern, Switzerland and ${ }^{4}$ Department of Pediatrics, University of Bern, Inselspital, CH-3010 Bern, Switzerland

Email: Marion Jetter - marion.jetter@ifik.unibe.ch; Nadja Heiniger - nadja.heiniger@ucsf.edu; Violeta Spaniol - violeta.spaniol@ifik.unibe.ch; RolfTroller - rolf.troller@ifik.unibe.ch; André Schaller - adre.schaller@dkf.unibe.ch; Christoph Aebi* - christoph.aebi@insel.ch

* Corresponding author

Published: 4 September 2009

BMC Microbiology 2009, 9:188 doi:10.1|86/|47|-2180-9-188
Received: 16 March 2009

Accepted: 4 September 2009

This article is available from: http://www.biomedcentral.com//47|-2180/9//88

(C) 2009 Jetter et al; licensee BioMed Central Ltd.

This is an Open Access article distributed under the terms of the Creative Commons Attribution License (http://creativecommons.org/licenses/by/2.0), which permits unrestricted use, distribution, and reproduction in any medium, provided the original work is properly cited.

\begin{abstract}
Background: The outer membrane protein M35 is a conserved porin of type I strains of the respiratory pathogen Moraxella catarrhalis. It was previously shown that M35 is involved in the uptake of essential nutrients required for bacterial growth and for nasal colonization in mice. The aim of this study was (i) to characterize the potential roles of M35 in the host-pathogen interactions considering the known multifunctionality of porins and (ii) to characterize the degree of conservation in the phylogenetic older subpopulation (type 2) of $M$. catarrhalis.
\end{abstract}

Results: Isogenic m35 mutants of the type I strains O35E, 300 and 4I5 were tested for their antimicrobial susceptibility against I5 different agents. Differences in the MIC (Minimum Inhibitory Concentration) between wild-type and mutant strains were found for eight antibiotics. For ampicillin and amoxicillin, we observed a statistically significant 2.5 to 2.9-fold MIC increase ( $<<$ 0.03 ) in the $m 35$ mutants. Immunoblot analysis demonstrated that human saliva contains anti-M35 IgA. Wild-type strains and their respective $\mathrm{m} 35$ mutants were indistinguishable with respect to the phenotypes of autoagglutination, serum resistance, iron acquisition from human lactoferrin, adherence to and invasion of respiratory tract epithelial cells, and proinflammatory stimulation of human monocytes. DNA sequencing of $m 35$ from the phylogenetic subpopulation type 2 strain 287 revealed $94.2 \%$ and $92.8 \%$ identity on the DNA and amino acid levels, respectively, in comparison with type I strains.

Conclusion: The increase in MIC for ampicillin and amoxicillin, respectively, in the M35-deficient mutants indicates that this porin affects the outer membrane permeability for aminopenicillins in a clinically relevant manner. The presence of $\lg A$ antibodies in healthy human donors indicates that M35 is expressed in vivo and recognized as a mucosal antigen by the human host. However, immunoblot analysis of human saliva suggests the possibility of antigenic variation of immunoreactive epitopes, which warrants further analysis before M35 can be considered a potential vaccine candidate. 


\section{Background}

Moraxella catarrhalis is an exclusively human, mucosal respiratory tract commensal and pathogen causing between $5 \%$ [1] and $20 \%$ of cases of acute otitis media in children [2] across all regions of the world. The recent introduction of routine infant immunization with pneumococcal conjugate vaccines has - in some studies [3] - led to a substantial increase in otitis media caused by $M$. catarrhalis [3]. It is thus a major cause of the most common bacterial infection in children requiring medical attention. M. catarrhalis also triggers approximately 10\% acute exacerbations of chronic obstructive pulmonary disease (COPD) in adults [4]

In our attempts to identify cold shock regulated outer membrane proteins (OMP) of M. catarrhalis [5] we investigated a recently described OMP called M35. We found no evidence of cold shock regulation, but the construction of an isogenic mutant lacking the expression of a currently incompletely described OMP of M. catarrhalis provided us with the opportunity to conduct a phenotypic analysis of the function of M35. Meanwhile, in an elegant series of experiments, Easton and co-workers [6] demonstrated that M35 is a typical Gram-negative OM porin, which also is essential for short-term nasal colonization of mice. Importantly, porins of Gram-negative bacteria not only assure bacterial homeostasis by acting as transport channels, but are also known to afford virulence mechanisms such as adhesion, invasion [7-11], and pro-inflammatory stimulation. [11-17]. In addition, porins are often involved in antimicrobial resistance [18-26]. Porins of $M$. catarrhalis have received little attention in the scientific literature. Gotho et al. described the permeability for betalactam antibiotics across the OM of $M$. catarrhalis suggesting that porins may be involved [27]. Lafontaine et al investigated the porin-like OMP CD, which acts as an adhesin on lung cells [7]. Thus, M35 is currently the only well characterized porin of $M$. catarrhalis $[6,28]$.

The aims of the present study were (i) to provide an overview of phenotypic differences between the strains $\mathrm{O} 35 \mathrm{E}$, 300 and 415 and their respective isogenic $m 35$ mutants, (ii) to investigate whether M35 is a human mucosal anti- gen and thus a potential vaccine candidate, (iii) to evaluate the role of M35 in the susceptibility of $M$. catarrhalis to various classes of antimicrobial agents, and (iv) to provide the DNA sequence $m 35$ of strain 287 , which is a representative of the phylogenetically older major lineage (type 2) of M. catarrhalis [29].

\section{Methods \\ Bacterial strains and culture conditions}

The M. catarrhalis strains and their isogenic m35 mutants used in this study are listed in Table 1 . All strains were cultured at $37^{\circ} \mathrm{C}$ and $150-200 \mathrm{rpm}$ in brain heart infusion (BHI) broth (Difco, Detroit, MI) or on BHI agar plates in an atmosphere containing $5 \% \mathrm{CO}_{2}$. Media were supplemented with kanamycin $(20 \mu \mathrm{g} / \mathrm{ml})$ for culturing of the mutants. To investigate growth under different osmotic conditions, strains were cultured in BHI broth overnight at $37^{\circ} \mathrm{C}$ and $150 \mathrm{rpm}$. One $\mathrm{ml}$ of overnight culture was diluted 1:100 in fresh BHI supplemented with $0.25 \mathrm{M}, 0.5$ $\mathrm{M}$ or $1.0 \mathrm{M} \mathrm{NaCl}$, respectively, and incubated at $37^{\circ} \mathrm{C}$ and $150 \mathrm{rpm}$. During cultivation to the stationary phase cell density was measured at $\mathrm{OD}_{600}$. The effect of exposure to different acidic environments was measured by growing bacteria in BHI broth overnight, harvesting and resuspending them in $20 \mathrm{mM} \mathrm{Na} \mathrm{HPO}_{4} / \mathrm{NaH}_{2} \mathrm{PO}_{4}, 1 \mathrm{mM}$ $\mathrm{MgCl}_{2}, 25 \mathrm{mM}$ L-arginine adjusted to $\mathrm{pH} 4.0, \mathrm{pH} 5.0, \mathrm{pH}$ 6.0 , or $\mathrm{pH} 7.0$, respectively. Suspensions were incubated for $2 \mathrm{~h}$ and $4 \mathrm{~h}$, respectively, at $37^{\circ} \mathrm{C}$, and the number of viable bacteria was quantified by plating of serial dilutions. Iron utilization experiments were performed by a disk feeding assay applying $5 \mu$ l of iron-saturated human lactoferrin $(10 \mathrm{mg} / \mathrm{ml})$ to sterile filter disks [30]. BHI agar plates were previously iron depleted by adding deferoxamine mesylate (Desferal, Novartis, Basel, Switzerland) to a final concentration of $30 \mu \mathrm{M}$ and incubated at $4^{\circ} \mathrm{C}$ overnight before use. Escherichia coli $\mathrm{DH} 5 \alpha$ was grown on Luria-Bertani (LB) agar plates or in LB broth.

\section{DNA methods}

Plasmids were isolated using the Wizard Plus SV Miniprep DNA purification system (Promega Corp., Madison, Wis.) DH5 $\alpha$ was transformed as described previously [31]. Restriction enzymes were purchased from New England

Table I: Bacterial strains used in this study

\begin{tabular}{|c|c|c|}
\hline Strain & Description & Source or reference \\
\hline M. catarrhalis $\mathrm{O} 35 \mathrm{E}$ & middle ear isolate & {$[65]$} \\
\hline M. catarrhalis O35E.m35 & isogenic mutant strain, $\operatorname{kan}^{R}$ & this study \\
\hline M. catarrhalis 300 & nasopharyngeal isolate from child & {$[35]$} \\
\hline M. catarrhalis $300 . \mathrm{m} 35 \mathrm{E}$ & isogenic mutant strain, $\mathrm{kan}^{\mathrm{R}}$ & this study \\
\hline M. catarrhalis 415 & nasopharyngeal isolate from child & {$[35]$} \\
\hline $\begin{array}{l}\text { M. catarrhalis } 415 . \mathrm{m} 35 \\
\text { M. catarrhalis } 287\end{array}$ & $\begin{array}{l}\text { isogenic mutant strain, } \mathrm{kan}^{\mathrm{R}} \\
\text { nasopharyngeal isolate from child }\end{array}$ & $\begin{array}{l}\text { this study } \\
{[35]}\end{array}$ \\
\hline Escherichial coli DH5 $\alpha$ & Host strain for plasmid constructs & [66] \\
\hline
\end{tabular}


Biolabs, Inc., Beverly, MA. Electrocompetent M. catarrhalis was prepared and DNA was electroporated as described [32]. DNA sequencing was performed by using an ABI PRISM 310 genetic analyzer (PE Biosystems, Rotkreuz, Switzerland) with the Big Dye Terminator cycle sequencing ready reaction kit (PE Biosystems, Rotkreuz, Switzerland). Sequences were analyzed with the Lasergene software (DNASTAR Inc., Madison, WI). For sequencing of $m 35$ of strain 287, DNA was amplified using the primers m35B5 (5'-TCGATACCAGAACACTACCTAAGC-3'), m35F2 (5' -GTCTGAGGGCAAGGTAGGCG-3'), m35RMJ1 (5' -CGTAGCAGTTTTCATCTCACCAC 3'), m35F3 (5'CTTGCTCTAGCAACCGCAG-3'), m35R3 (5'-GCAAGACCTAGGTAAGTATC-3') and m35FMJ4 (5'-TGCGTGCATGGGTCGTGA-3').

\section{Construction of the isogenic mutants O35E.m35, 300.m 35 and $415 . \mathrm{m} 35$}

Part of the m35 gene of the strains O35E, 300 and 415, respectively, was amplified using forward primer $m 35 \mathrm{~F} 3$ (5'-CTTGCTCTAGCAACCGCAG-3') and reverse primer

A

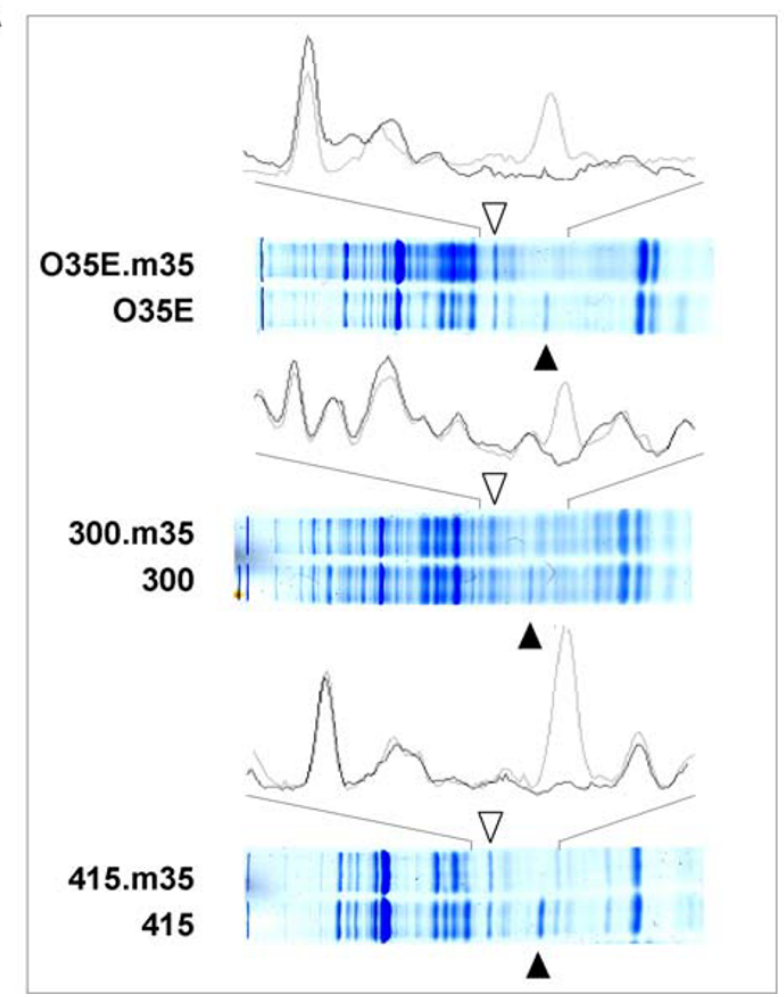

m35B5 (5'-TCGATACCAGAACACTACCTAAGC-3'). PCR products were ligated into the BamHI restriction site of pGEM-T-Easy pUC4K (Promega, Madison, USA). The kanamycin cassette was ligated into the AvrII restriction site of the $m 35$ insert. The resulting construct, $\Delta m 35: k a n$, was used for electroporation of the competent strains O35E, 300 and 415, respectively. Transformants were selected on BHI agar plates containing $20 \mu \mathrm{g} / \mathrm{ml}$ of kanamycin. Insertional inactivation of $m 35$ was confirmed by PCR analysis, sequencing, Southern blot analysis (data not shown) and immunoblotting (figure 1).

\section{Preparation of OMP}

OMP were prepared by the EDTA buffer method as described [33]. Bacteria were harvested from a stationary phase culture, resuspended in EDTA buffer $(0.05 \mathrm{M}$ $\mathrm{Na}_{2} \mathrm{HPO}_{4}, 0.15 \mathrm{M} \mathrm{NaCl}, 0.01 \mathrm{M}$ EDTA, ph 7.4), homogenized and incubated at $55^{\circ} \mathrm{C}$ at $300 \mathrm{rpm}$ for $1 \mathrm{~h}$. Cells and cell debris were eliminated by centrifugation at $10,000 \times$ $\mathrm{g}$ for $15 \mathrm{~min}$ at $4^{\circ} \mathrm{C}$. Finally, OMP were collected by ultracentrifugation at $100.00 \times \mathrm{g}$ for $2 \mathrm{~h}$ at $4^{\circ} \mathrm{C}$.
B

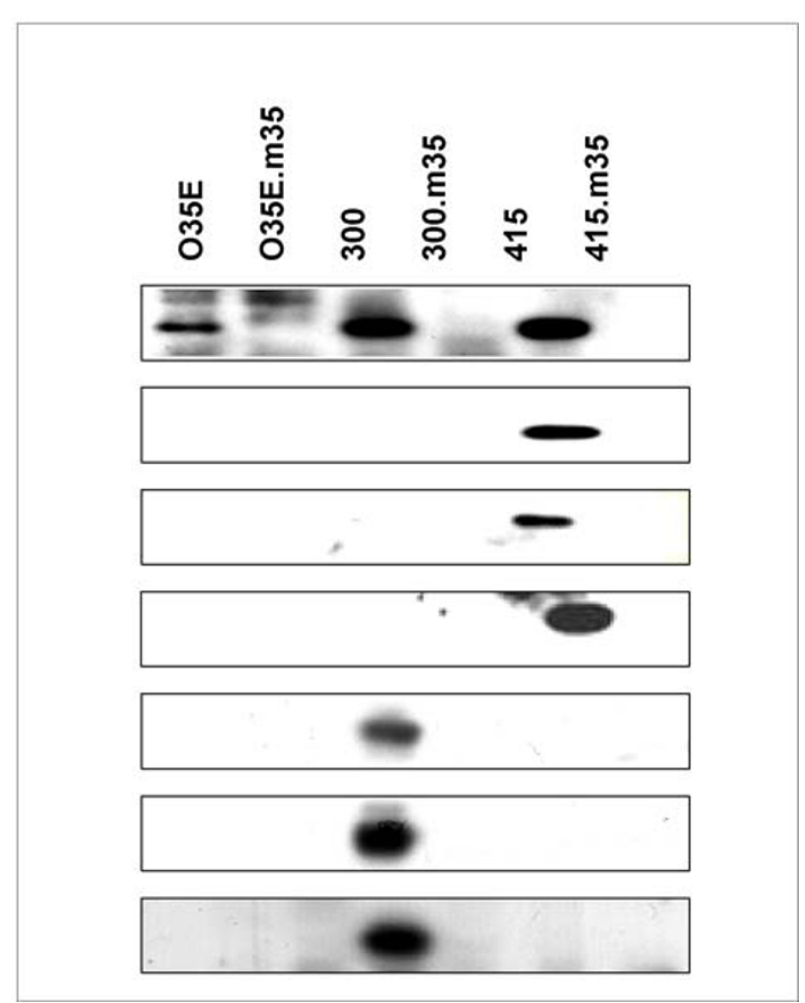

\section{Figure I}

(A) SDS PAGE of M. catarrhalis OMP of the strains O35E, 300 and 415 together with their respective m35 knock-out mutants. Black triangles show the position of the M35 protein band at $36 \mathrm{kDa}$. White triangles show the position of the $40 \mathrm{kDa}$ protein. The spectra display the intensity of each protein band determined by the AlphaEaseFC ${ }^{\circledR}$ software. Light lines show the wild-type strain, dark lines show the respective M35 mutant strains. (B) Western Blot analysis for human salivary IgA against M35 of the strains O35E, 300 and $4 I 5$ from seven healthy donors. The isogenic m35 mutants were included as negative controls. 


\section{D-Gel electrophoresis and MALDI-TOF}

Analysis of M35 and other OMP spots of strain O35E was performed a described previously [34], except for the precipitation of the OMP, which was omitted.

\section{SDS-PAGE gel electrophoresis and immunoblot for detection of human anti-M35 IgA}

Samples were resolved by SDS-PAGE using a $7.5 \%$ polyacrylamide gel. Band intensity was quantified using the AlphaEaseFC ${ }^{\circledast}$ program from Inotech, Inc. Antibody detection was performed by Western blot analysis. Proteins were transferred to polyvinylidene difluoride (PVDF) membranes (Immobilon-P; Millipore Corp., Bedford, MA). IgA binding was detected using human saliva samples as primary antibody source and goat anti-human IgA, respectively, labeled with horseradish peroxidase (SIGMA) as secondary antibody. Super Signal West Pico Chemiluminescent Substrate (Pierce Chemical Co., Rockford, IL) was used for detection of antibody binding. Unstimulated human saliva was collected from healthy volunteers using Salivette sponges ${ }^{\circledast}$ (Sarstedt, Nümbrecht, Germany), centrifuged for 5 minutes at $2000 \mathrm{rpm}$ and stored at $-20^{\circ} \mathrm{C}$. All volunteers were laboratory researchers and provided oral informed consent. Sampling of saliva from healthy volunteers was approved by the local ethics committee.

\section{Antimicrobial resistance testing}

The minimum inhibitory concentrations (MIC) of penicillin, ampicillin, amoxicillin, amoxicillin-clavulanate, cefuroxime, ceftriaxone, imipenem, meropenem, erythromycin, doxycycline, gentamicin, vancomycin, ciprofloxacin, levofloxacin, and moxifloxacin were determined by E-test ${ }^{\circledast}$ (AB Biodisk, Sweden) according to the manufacturer's instructions.

\section{Autoagglutination and serum bactericidal assay}

Overnight cultures were resuspended in PBS and adjusted to an $\mathrm{OD}_{600}$ of 2.0 in glass tubes. $\mathrm{OD}_{600}$ of the supernatants were determined after 15 and 60 minutes, respectively. Serum bactericidal assay were performed as previously reported [35].

\section{Human cell lines and growth conditions}

Chang conjunctival cells and A549 lung cells were maintained in Eagle's minimal essential medium (Invitrogen, Basel, Switzerland) supplemented with $10 \%$ of heat-inactivated fetal calf serum, 100 units/ml penicillin, $100 \mu \mathrm{g} /$ $\mathrm{ml}$ streptomycin, and $2 \mathrm{mM} \mathrm{L}$-glutamine at $37^{\circ} \mathrm{C}$ in $5 \%$ $\mathrm{CO}_{2}$. The THP-1 human monocytic cell line was maintained in RPMI 1640 (Lonza, Basel, Switzerland) supplemented with $2 \mathrm{mM}$ L-glutamine, $10 \%$ heat-inactivated fetal calf serum, $0.05 \mathrm{mM} \beta$-mercaptoethanol, $10 \mathrm{mM}$ HEPES, $100 \mathrm{units} / \mathrm{ml}$ penicillin and $100 \mu \mathrm{g} / \mathrm{ml}$ streptomycin at $37^{\circ} \mathrm{C}$ in $5 \% \mathrm{CO}_{2}$.

\section{Adherence and Invasion assay}

The ability of $M$. catarrhalis to adhere to and invade human epithelial cells in vitro was measured as described previously [36]. Adherence and invasion was assessed on both Chang conjunctival cells and A549 lung cells as described [36,37]. Each strain was analyzed in triplicate in each experiment.

\section{Proinflammatory activity of M35 on human monocytes}

The pro-inflammatory potential of $M$. catarrhalis OMP was described previously [38]. To investigate if M35 is an important mediator of proinflammatory cytokine release on the bacterial cell surface, THP- 1 cells $\left(1 \times 10^{6} / \mathrm{ml}\right)$ were stimulated with different concentrations $\left(1 \times 10^{5} / \mathrm{ml}, 1 \times\right.$ $10^{6} / \mathrm{ml}$, or $1 \times 10^{7} / \mathrm{ml}$ ) of heat inactivated strain O35E or the O35E.m35 mutant and incubated for $18 \mathrm{~h}$ at $37^{\circ} \mathrm{C}$ and $5 \% \mathrm{CO}_{2}$. After incubation, cells were centrifuged for $2 \mathrm{~min}$ at $11,800 \times \mathrm{g}$ and supernatants were stored at $80^{\circ} \mathrm{C}$. Cytokines were measured using the R\&D Systems DY208 for human CXCL8/IL-8 and R\&D Systems DY210 for human TNF $\alpha / T N F S F 1 A$ (R\&D, Minneapolis, USA), respectively.

\section{Statistical analysis}

Comparison of several test series was evaluated by analysis of variance (ANOVA). The significance of differences between treatment and control groups was determined using the two-tailed $t$-test. $\mathrm{P}<0.05$ was considered as statistically significant. Each value represents the mean \pm one standard deviation of at least three independent experiments performed in triplicate.

\section{Results}

In vitro growth of m35 mutants

Standard growth curves of the three wild-type/mutant pairs in BHI broth revealed no difference in growth velocity measured as broth density at $\mathrm{OD}_{600}$ (data not shown). Because porins are frequently involved in stress responses of bacteria against changes in osmolarity or pH [39-41], we investigated the wild-type/mutant pairs with respect to growth at various osmotic (supplementation of BHI with $0.25,0.5$ and $1 \mathrm{M} \mathrm{NaCl}$ ) and acidic (pH 4-7) conditions (figure 2). Again, wild-type strains and their respective mutants behaved identically.

\section{M35 knockout is not associated with upregulation of a 40 kDa OMP}

Easton et al. [6] described the upregulation of a $40 \mathrm{kDa}$ protein in one of their isogenic $m 35$ mutants. In order to confirm this observation, we compared Coomassie-blue stained OMP profiles of our three strains with their respective $m 35$ mutants, but failed to detect any discernible upregulation of other OMP as determined by measuring protein band intensities (figure 1A). Thus, removal of M35 does not appear to affect the OMP composition 


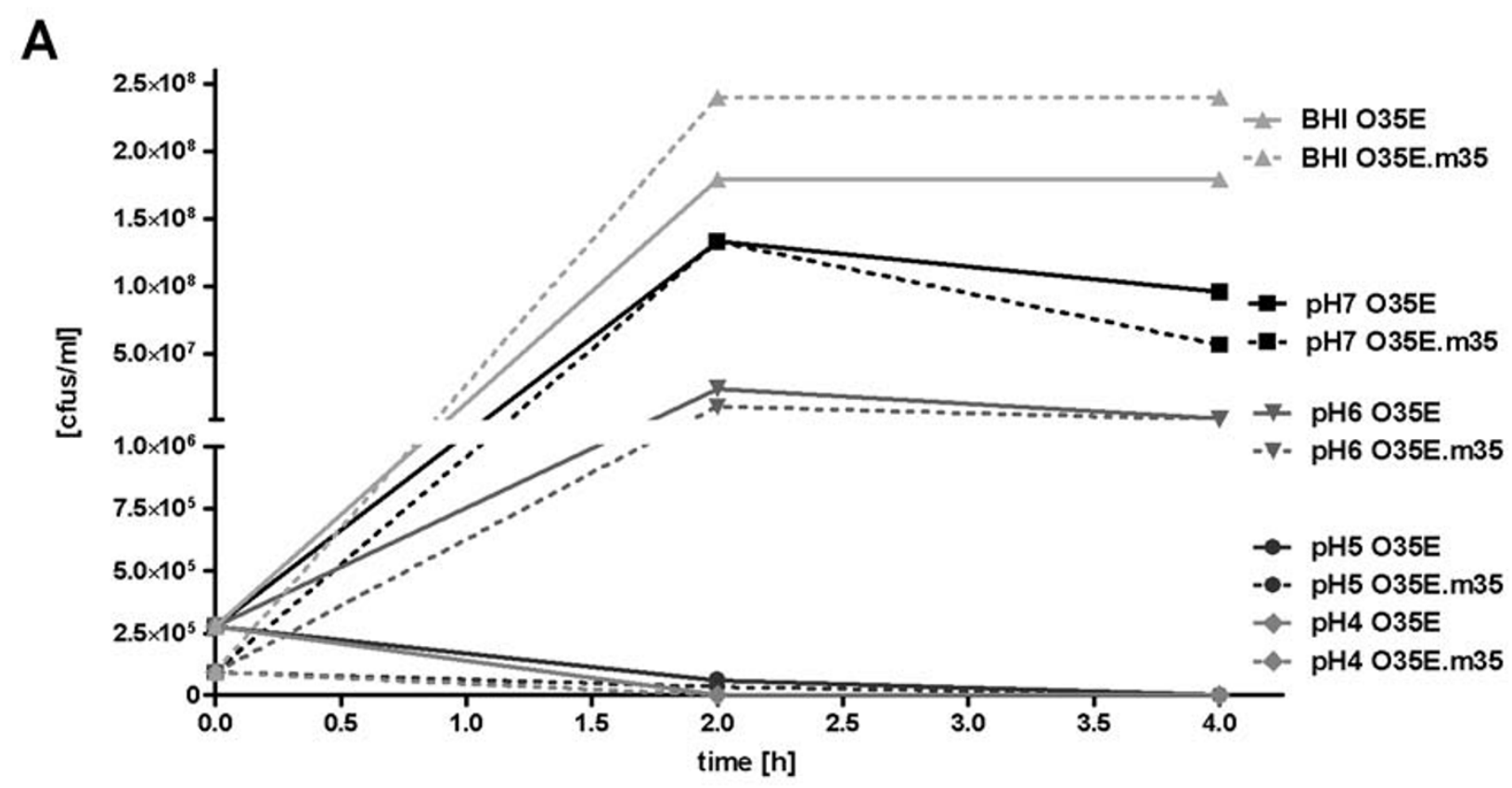

B

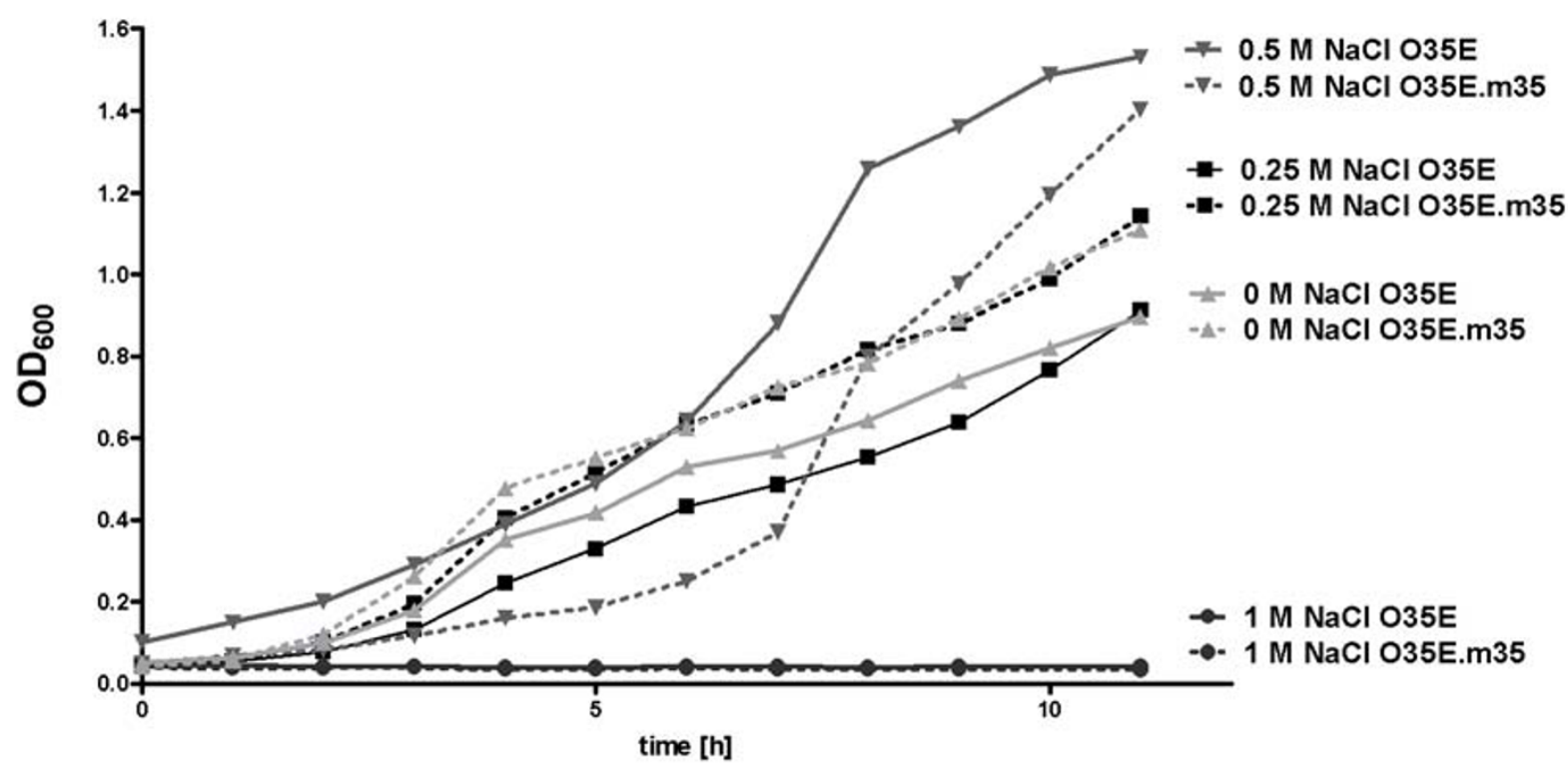

Figure 2

Growth of $M$. catarrhalis O35E and its isogenic m 35 mutant under acidic (A) and osmotic (B) stress. (A) The effect of exposure to different acidic conditions was measured by growing bacteria in $\mathrm{BHI}$ adjusted to $\mathrm{pH} 4.0, \mathrm{pH} 5.0, \mathrm{pH} 6.0$, or $\mathrm{pH} 7.0$, respectively. Suspensions were incubated for $2 \mathrm{~h}$ and $4 \mathrm{~h}$, respectively, and the number of viable bacteria was quantified by plating on $\mathrm{BHI}$ agar plates. (B) Different osmotic conditions were investigated by culturing bacteria in $\mathrm{BHI}$ supplemented with $0.25 \mathrm{M}, 0.5 \mathrm{M}$ or I.0 M NaCl . During cultivation to the stationary phase bacterial density was measured at $\mathrm{OD}_{600}$. 
when bacteria are grown in BHI. Taken together, the data presented thus far indicate that M35 is not essential for growth in vitro and that its removal from the OM does not otherwise affect the OMP composition.

\section{M35 is expressed in vivo}

The human mucosal antibody response to OM components of $M$. catarrhalis has been described in detail [4245], but M35 has never been paid specific attention. In order to search for human antibodies against M35, OMP of the strains O35E, 300, 415 and their isogenic mutants were resolved by SDS-PAGE, transferred to PVDF membranes, and incubated with human saliva for detection of IgA. Western Blot analysis for anti-M35 IgA with 7 different donors resulted in antibody signals to all three strains with the strains 300 and 415 displaying broader immunogenicity than O35E (figure 1B). Four of seven donor saliva contained anti-M35 IgA against strain 300 and 415, respectively. One donor displayed anti-M35 IgA for all three strains. OMP of the $m 35$ mutants were used as negative controls (figure 1B). These data suggest that $M$. catarrhalis expresses M35 in vivo and that the mucosa-associated lymphoid tissue recognizes M35 as an antigen.

\section{Aminopenicillin susceptibility is mediated by M35}

One of the major bacterial strategies for drug resistance is barrier protection, which limits the intracellular access of antimicrobial agents [18]. The influx of large, charged molecules is controlled by porins, which allow passive penetration of hydrophilic molecules of several classes of antibiotics [19-21]. Thus, porin-mediated OM permeability is expected to affect susceptibility to antimicrobial agents $[18,22]$. To investigate this, E-tests were performed with the mutants O35E.m35, 300.m35, 415.m35 and their respective wild-type parent strains. There were no differences in MIC for penicillin G, ceftriaxone, meropenem, erythromycin, doxycycline, gentamicin, and vancomycin between wild-type and mutant strains, respectively. For quinolones (ciprofloxacin, levofloxacin and moxifloxacin), cefuroxime and imipenem there was a minor, but consistent 1.4 -fold increase in the MIC of the mutants (data not shown). For ampicillin and amoxicillin, however, there was a statistically significant increase in the MIC of the mutants (2.5 to 2.9-fold) in comparison with their respective wild-types (figure $3 \mathrm{~A} / \mathrm{B})(\mathrm{p}=0.003$ 0.023 ). Interestingly, at an approximately 10 -fold lower level, this was also found for amoxicillin-clavulanate (figure $3 \mathrm{C}$ ).

\section{Expression of M35 and putative virulence traits of $M$. catarrhalis}

The capacity to autoagglutinate is mediated by hemagglutinin (also called Moraxella IgD-binding protein) [46], but some hemagglutinin knock-out mutants still autoagglutinate (unpublished data). Thus, we investigated whether the absence of M35 affected autoagglutination, but failed to identify any difference between strain $\mathrm{O} 35 \mathrm{E}$ and O35E.m35 (data not shown). Similarly, resistance of $M$. catarrhalis to human complement, which is associated with disease-causing isolates [47-49] and which requires expression of several OMP [37,50-52], was not impaired by the lack of M35 (data not shown). Growth of M. catarrhalis in vivo is dependent on the ability to acquire iron from the human host by retrieving $\mathrm{Fe}^{3+}$ from ironcontaining host proteins by a number of specific binding and uptake systems [30,53-59]. Because of its abundance on mucosal surfaces, we chose to investigate the ability of the $m 35$ mutant to use iron bound to human lactoferrin using a standard disk feeding assay on iron depleted BHI agar plates [30]. The experiment resulted in no differences in growth between the three $m 35$ mutants and their respective wild-type parents (data not shown).

\section{Adherence and invasion of the $\mathrm{m} 35$ mutant}

The abilities of a pathogen to adhere to and invade epithelial host cells, respectively, are major virulence factors. Adhesins and invasins usually are OMP $[5,36,60,61]$, some of which also act as porins [7-11]. To investigate if M35 mediates adherence and invasion assays were performed on Chang conjunctival cells as well as on A549 lung cells. Adherence of the O35E.m35 mutant was as efficient as that of its wild-type parent strain (figures 4A/B). Similarly, no differences were found for the capacity to invade these cell types (figures 4C/D) in gentamicin protection assays.

\section{Proinflammatory activity of M35 on human monocytes}

Proinflammatory activity is typically induced by OMP, lipopolysaccharide or lipoteichoic acids. Porins have also been described to induce proinflammatory cascades by activating innate immune receptors mediating the expression of several chemokines and cytokines [11-17]. We investigated M35 with regard to its proinflammatory effect on human monocytes. THP-1 cells were stimulated with strain O35E or its O35E.m35 mutant overnight and cytokine release in the supernatant was measured by determining the concentrations of IL- 8 and TNF $\alpha$ by ELISA. There was no difference in the release of IL- 8 and $\mathrm{TNF} \alpha$, respectively, between wild-type and mutant (data not shown).

\section{M35 sequence analysis of type 2 strain $\mathbf{2 8 7}$}

M35 is nearly $100 \%$ conserved among type 1 strains of $M$. catarrhalis [28]. To determine if this is also true for the other major phylogenetic subpopulations of $M$. catarrhalis, $m 35$ of type 2 strain 287 was sequenced and analyzed by bioinformatics. In comparison with type 1 strain O35E, there was a divergence of $5.8 \%$ at the DNA level consisting mainly of point mutations (figure 5). Unexpectedly, these DNA mutations lead to an even greater 

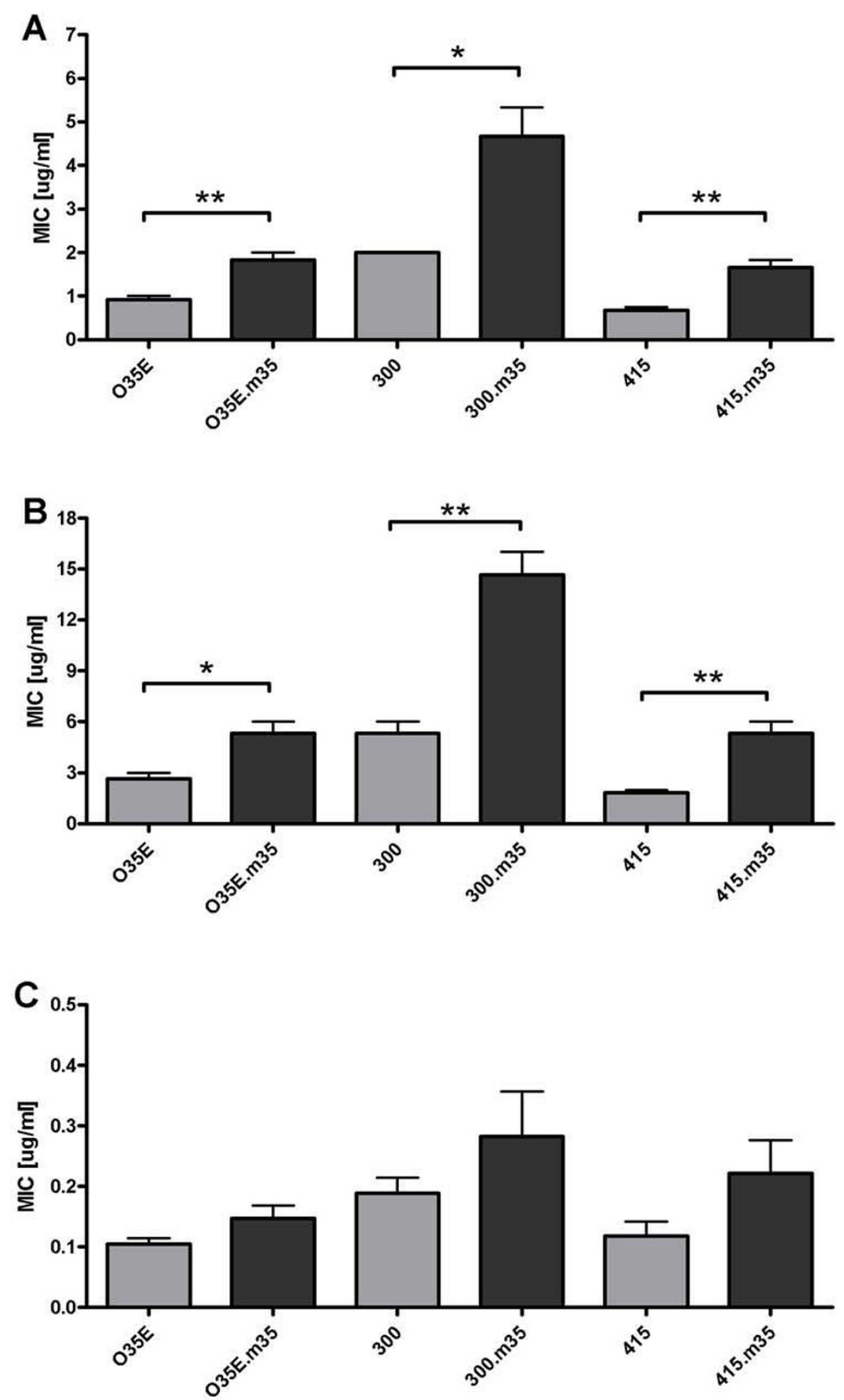

Figure 3

E-tests of the strains $\mathrm{O35E}, 300$ and 415 and their respective isogenic $\mathrm{m} 35$ mutants with ampicillin (A), amoxicillin (B) and amocixillin-clavulanate (C). Bacteria were cultured on agar plates together with E-test strips overnight. Bars show the minimum inhibitory concentration (MIC) for each antibiotic. Data are presented as means $\pm I S D(n=3)$. $* p<0.05$ for wild-type vs. respective mutant. 

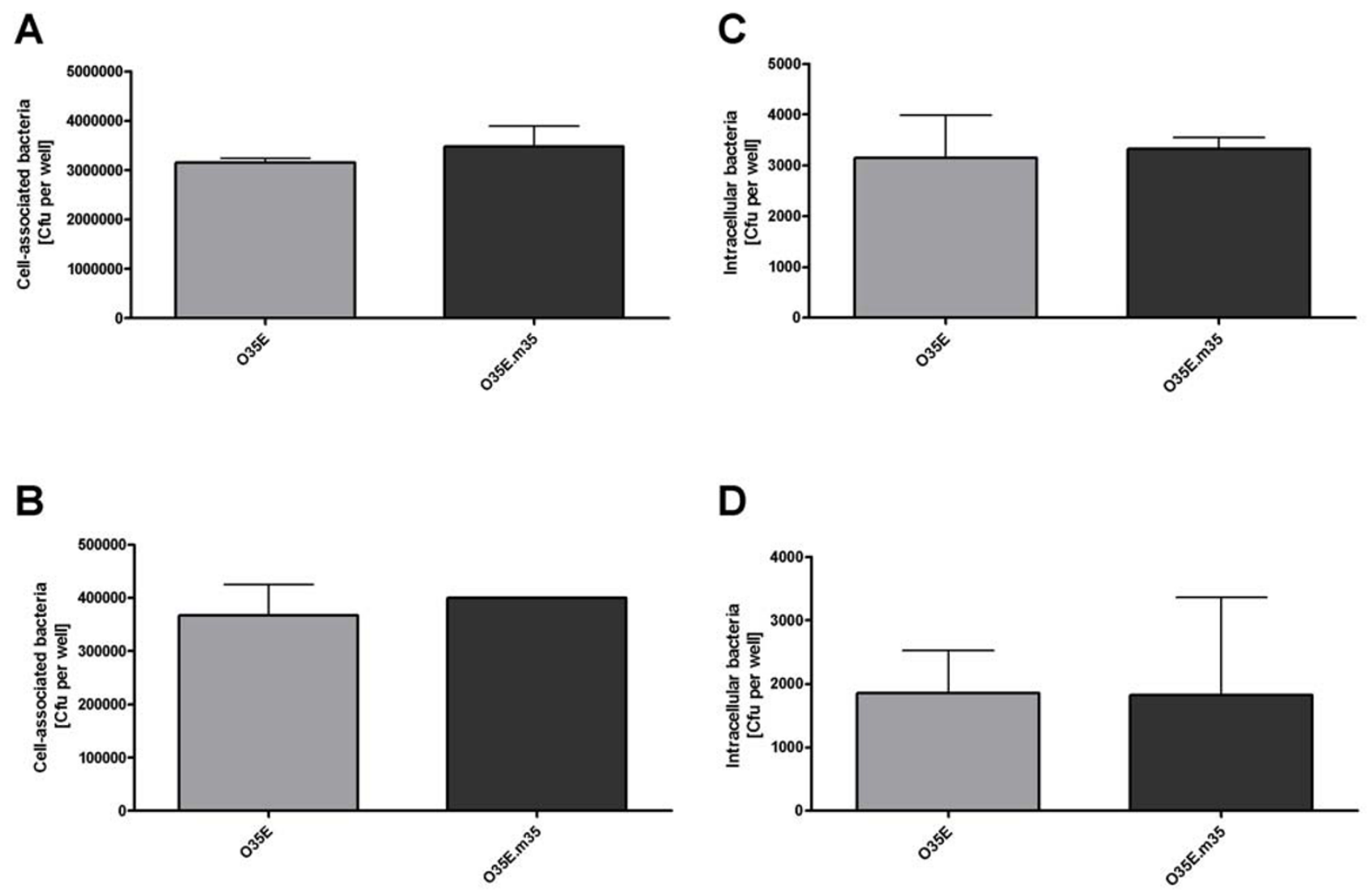

Figure 4

Adherence to Chang conjunctival cells (A) and A549 lung cells (B) and invasion into Chang cells (C) and A549 cells (D) by M. catarrhalis O35E and its isogenic knock-out mutant O35E. $\mathrm{m} 35$. The cells were infected and, after 30 min for adherence and $3 \mathrm{~h}$ for invasion, total cell-associated bacteria or intracellular bacteria, respectively, were quantitated by dilution plating. Data are represented as means \pm I SD $(n=3)$ of at least three separate experiments.

divergence of $6.1 \%$ at the amino acid sequence level (figure 6). This corresponds to a substantial number of missense mutations.

\section{Discussion}

Porins are essential components of the gram-negative outer membrane and contribute to nutrient transport, antimicrobial resistance, response to osmostress and other processes, which are essential for bacterial homeostasis. M35 is the first functionally characterized OM porin of $M$. catarrhalis [28] and as of today all isolates examined carry a highly conserved $m 35$ gene on their chromosome. This may indicate that strains not expressing M35 are not viable in vivo, but the only evidence in support of this hypothesis is the observation that a $m 35$ mutant was unable to colonize the nasal mucosa of mice [6], which are not a natural host species for $M$. catarrhalis.

Our observation that healthy humans have mucosal IgA directed against M35 indicates that this protein is expressed in vivo. However, the fact that some salivary samples did not recognize all three M35 proteins tested suggests that either (i) antigenic variation occurs at immunoreactive, surface exposed epitopes, or (ii) it is a weak antigen and some individuals lose or never acquire antiM35 IgA, or (iii) some isolates lack expression of M35 in vivo. If the latter were the case, screening of large collections of clinical $M$. catarrhalis isolates should identify strains either lacking a m35 gene or isolates carrying silent genes. The answer to this question is of clinical relevance, because our data indicate that the absence of M35 is a previously unknown mechanism of aminopenicillin resistance in $M$. catarrhalis. This effect could occur in vivo by alterations in porin expression to prevent antibiotic influx, which is a well known mechanism of resistance in other pathogens $[18,22]$, and which often is associated with the expression of degradative enzymes to confer high level resistance $[23,24]$. The specificity of M35 for aminopenicillins could be explained by an effect Bezrukov et al described for OmpF of E. coli. They found that the 


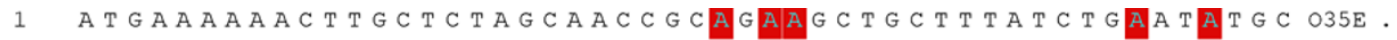
1 A T GAAAAACT T G T T TA CAACC G T T T T G T G T T TA T T T T T T T G 287.5 51 T 51 T GCACAAGCAGCACC GACCAT T T C G T A A A C G T T T T G A T T T T G T G 287.5

101 C CA A CA TACTGATACAACT TATAAT TCAGGTCTTGTACA T TATCTGAA 035E.

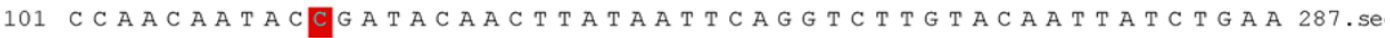

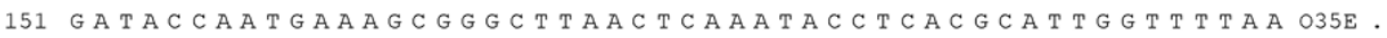
151 GATACCAATGAAAGCG G G T TAACTCAAATACCTCACGCATTG T T T TA 287.se 201 A G T T T T A A G T T TAA T G TA TACT TA T T T T T TA TCA A T T GA T O35E.

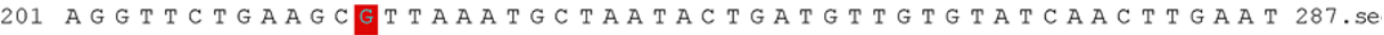

251 A TAAGA T T ACA T T A T G T T A T G T G G C A T A A T T T A A T T T G T G T O35E.

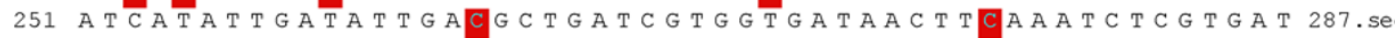

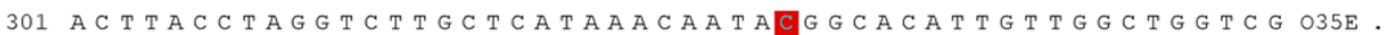

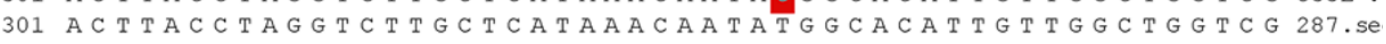

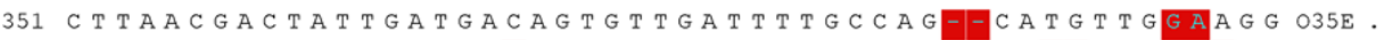

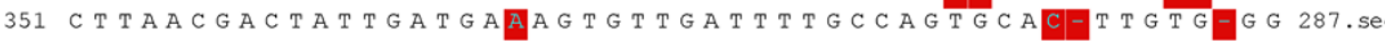

399 TA A TA A T T C G C T G A C T C G G T C TACT T T TA A T G C C C T C G T G C A A A O35E. 399 TA A TA T T T G C T G A A T C G T C C T A T T T T A T G C C C T C T T G C A A A 287.5

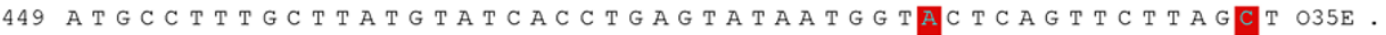

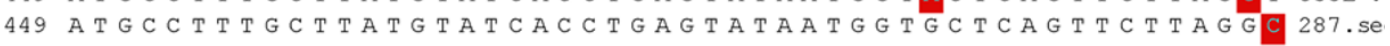

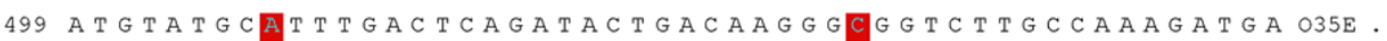

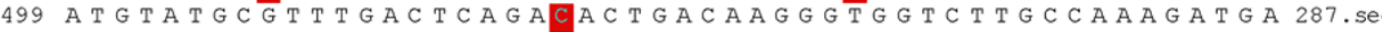

549 C C A G T T T G T G T G G T G C A A T TA TA G C C A G G C C T A T C A T G C A G T G O35E. 549 C C A T T T G T T T G G T G CA A T T TAGCACA G C C C TA T CA T G A A T G 287.se 599 C G A T T A T A T T A T A C G T T A T G A A T T A C A T C G C C T A T T G G C A C O35E.

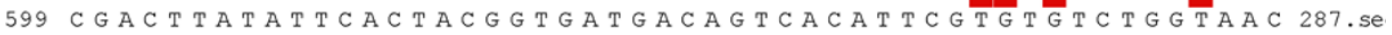
649 T A T G C G T T T C T C C A G C A T T G A T G TAG T G T T TA TA T C A A T T T CA GA O35E.

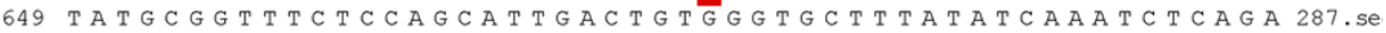

699 A T T T G T T T C G C T G C C A A A A T C A A A A C C A T C C T T T T T T G A G G A O35E. 699 A T T T G T T T C G T T C C A A A A T C A A A A A C C A T C C T T T T T T G A G G A 287.se

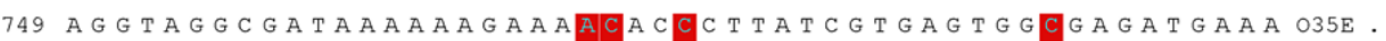

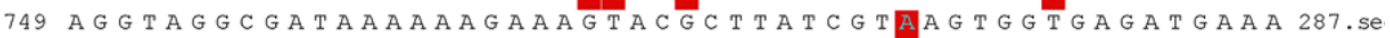

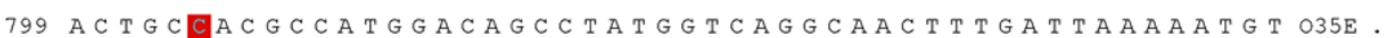
799 A C T G C TACGCCATGGACA G C TA T G T CA G G A A T T TAAT TAAAAT T 287.se

849 T G C T G G TA T G A T G G C A T G A T CAGT T G T T T T G T T T T G T T G TAAT O35E.

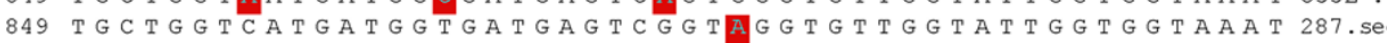

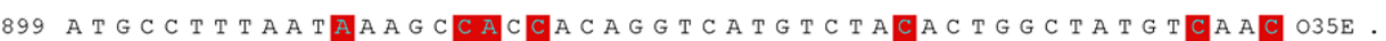

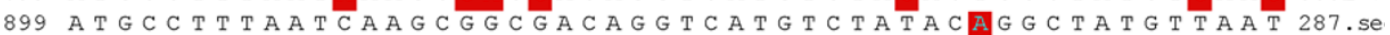

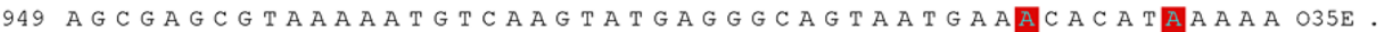

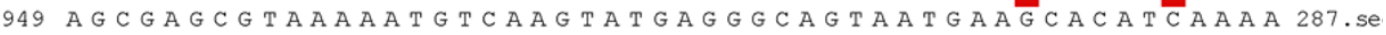

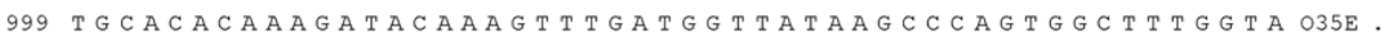

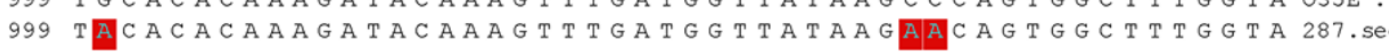

1049 T C G GCG C A G G T TA A A T A T A A T T T A A 1049 T C G G T G A G T T T A G A T A T A A T T C T A A

O35E. 287.se

\section{Figure 5}

M35 gene DNA sequence of type I strain O35E compared with type 2 strain 287 . The red squares indicate diverse nucleotides between the two strains. 
1 M K K L A L A T A E A A L S E $1 \mathrm{M} K \mathrm{~K}$ L A L A T A V A A L S V S A A \& A A P T I Y G K A F L 287.pri

31 T I D A N N T D T T Y N S G L V Q L S E D T N E S G L N S N O35E.p: $31 \mathrm{~T} V \mathrm{~V}$ A $\mathrm{N} N \mathrm{~T}$ D $\mathrm{T} T \mathrm{~T} N \mathrm{~S}$ G L V Q L S E D T N E S G L N S N 287.pr

61 T $S$ R I G F K G S E A L N A N T D V V Y Q L E Y K I D I D A O35E.p: 61 T $S$ R I G F K G S E A L N A N T D V V Y Q L E Y H I D I D A 287.pr

$91 \mathrm{D} R \mathrm{R} D \mathrm{~N}$ F K S R D T Y L G L A H K Q Y G T L L A G R L T T O35E.p:

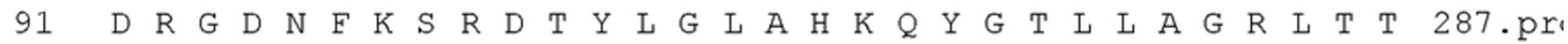

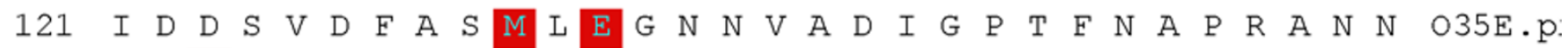
121 I $D E S$ V D F A S A L V G N N V A D I G P T F N A P R A N N 287.pr

151 A $F$ A Y V

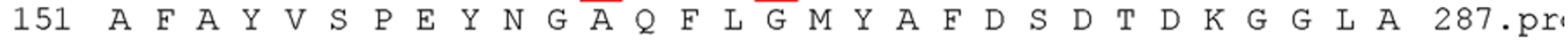

$181 \mathrm{~K} D \mathrm{D}$ Q $\mathrm{F}$ G V G A T Y S T G P I N A G A T Y I H Y G D D S H O35E.p: 181 K D D Q F G V G A T Y S T G P I N A G A T Y I H Y G D D S H 287.pr

211 I $R$ L $S$ G 211 I R V S G N Y A V S P A L T V G A L Y Q I S E F G V A A K N 287.pr

241 Q K A S P L S E G K V G D K K E N T L I V S G E M K T A T P O35E.p: 241 Q K A S P L S E G K V G D K K E S T L I V S G E M K T A T P 287.pr

271 W $T$ A Y G Q A T L I K N V A G N D G D E S V G V G I G G K Y O35E.p: 271 W T A Y G Q A T L I K N V A G H D G D E S V G V G I G G K Y 287.pr

301 A $F$ N 301 A F N Q A A T G H V Y T G Y V N S E R K N V K Y E G S N E A 287.pr

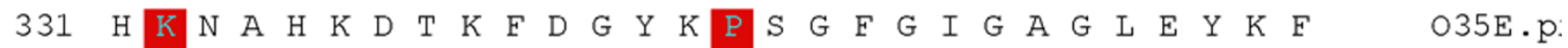

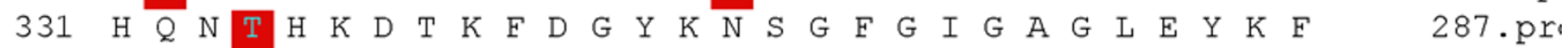

Figure 6

Deduced M35 amino acid sequence of type I strain O35E compared with type 2 strain 287 . The red squares indicate diverse amino acids between the two strains.

nature and position of specific charges on both the antibiotic molecule and the porin play a major role in these interactions $[25,26]$. Strong binding to the pore correlates with high diffusion rates whereas weak binding is associated with reduced diffusion. As of today, the only known mechanism of aminopenicillin resistance in M. catarrhalis is the expression of one of three chromosomally encoded BRO betalactamases, which are detectable in greater than $90 \%$ of clinical isolates [62] and explain the fact that the
MIC for amoxicillin-clavulanate in our experiments was at least 10 -fold lower than the MIC for amoxicillin. This finding indicates that clavulanate penetrates the OM by ways other than M35. It also demonstrates that, in the presence of clavulanate, the reduced amount of aminopenicillins still penetrating the OM in $m 35$ mutants suffices to inhibit growth. Thus, it appears that clavulanate inhibits essentially all betalactamase activity available and that naturally occurring isolates lacking M35 would not 
currently pose a substantial therapeutic problem in patients treated with betalactamase-resistant betalactams. However, standard dose or high dose amoxicillin still is the therapeutic standard for antimicrobial therapy of acute otitis media. Based on our data (figure 3), currently accepted pharmakinetic/pharmcodynamic (PK/PD) breakpoints for resistance against standard dose $(\geq 1.0 \mu \mathrm{g} /$ $\mathrm{ml})$ or high dose amoxicillin $(\geq 8 \mu \mathrm{g} / \mathrm{ml})$, respectively, [63] thus predict that isolates lacking functional M35 may display clinically relevant aminopenicillin resistance. This is particularly relevant for the treatment of acute otitis media. Drug concentrations reached in the middle ear cavity are low in comparison with serum concentrations [64] and treatment failure is typically caused by insufficient drug concentrations in the middle ear fluid [64]. The list of betalactam antibiotics tested in this study is not exhaustive and it is conceivable that other drugs may also be affected by $m 35$ mutations. Thus, further studies are needed to explore the potential impact of $m 35$ mutants on antimicrobial treatment failures.

Multiple phenotypic tests that we carried out with three wild-type/mutant pairs failed to uncover an additional functions attributable to M35. None of these results is particularly surprising. The strength of these "negative" data lies precisely in the fact that we did not study one, but three different isolates and their respective mutants, which, taken together, provide firm evidence that M35 is not involved these various phenotypes in vitro. The analysis of three different wild-type/mutant pairs also lead to the conclusion that knocking-out $m 35$ does not necessarily upregulate expression of a $40 \mathrm{kDa} \mathrm{OMP}$ as stated by Easton et al (figure 1A). Because these authors used a different strain, it is conceivable that they observed a strainspecific phenomenon, which does not represent the entire species. Finally, we sequenced $m 35$ of a strain belonging to the phylogenetically old, second subpopulation of $M$. catarrhalis [29], which differs from the younger subpopulation by a considerably larger genetic diversity [29]. Indeed, we found a substantial number of sequence deviations, which, interestingly, were even greater at the amino acid level than at the DNA level. It is thus conceivable that type 2 strains exhibit functional and/or antigenic differences with respect to M35, which warrant further investigation.

\section{Conclusion}

The significant increases in MIC for ampicillin and amoxicillin of the $m 35$ mutants indicate that the OM porin M35 is involved in the uptake of aminopenicillins. This is a previously unknown mechanism of resistance in $M$. catarrhalis. It remains to be elucidated whether naturally occurring, disease causing strains of $M$. catarrhalis devoid of functional M35 exist, and whether they may contribute to clinical treatment failure. The fact that normal human saliva contains anti-IgA indicates that M35 is expressed in vivo, but that antigenic variation may be greater than previously appreciated. Thus, further studies are needed before M35 can be considered a potential vaccine candidate against $M$. catarrhalis.

\section{Abbreviations}

ANOVA: analysis of variance; BHI: brain-heart infusion; COPD: chronic obstructive pulmonary disease; EDTA: ethylene-diamino-tetra-acetate; HEPES: Hydroxyethyl-1piperazinyl-ethansulfonic acid; IL-8: interleukin-8; LB: Luria-Bertani medium; MALDI-TOF: matrix-assisted laser desorption/ionisation-time of flight; OD: optical density; OM: outer membrane; OMP: outer membrane protein; PBS: phosphate-buffered saline; PCR: polymerase chain reaction; PVDF: polyvinylidene difluoride; RPMI: Roswell Park Memorial Institute medium; SDS-PAGE: sodium dodecyl sulphate-polyacrylamide gel electrophoresis; TbpB: transferring-binding protein B; TNFa: tumor-necrosis factor $\alpha$.

\section{Authors' contributions}

MJ participated in conceiving the study, conducted the majority of the experimental work and drafted the manuscript. NH constructed the $m 35$ mutants of the strains O35E, 300 and 415 . VS participated in conceiving the study. RT performed and interpreted the comparative SDS-PAGE analyses of wild-type and mutant strains. AS performed and analysed the MALDI-TOF experiments. CA was the principal investigator, conceived the study and finalized the manuscript. All authors read and approved the final manuscript.

\section{Acknowledgements}

This work was supported by the Swiss National Science Foundation (SNF) grants 3100A0-102246 and 3100A0-II6053 (to CA). Professor George Syrogiannopoulos, Larissa, Greece, provided the nasopharyngeal M. catarrhalis isolates 287,300 and 415 .

\section{References}

I. Marchant $C D$ : Spectrum of disease due to Branhamella catarrhalis in children with particular reference to acute otitis media. Am J Med 1990, 88(5A): I5S-I9S.

2. Palmu A, Herva E, Savolainen H, Karma P, Mäkela PH, Kilpi T: Association of clinical signs and symptoms with bacterial findings in acute otitis media. 2004, 38:234-242.

3. Eskola J, Kilpi T, Palmu A, Jokinen J, Haapakoski J, Herva E, Takala A, Kayhty H, Karma P, Kohberger R, et al.: Efficacy of a pneumococcal conjugate vaccine against acute otitis media. $N$ Engl $\mathrm{J}$ Med 200I, 344(6):403-409.

4. Murphy TF, Brauer AL, Grant BJ, Sethi S: Moraxella catarrhalis in chronic obstructive pulmonary disease: burden of disease and immune response. Am J Respir Crit Care Med 2005, I72(2): 195-199.

5. Heiniger N, Troller R, Meier PS, Aebi C: Cold shock response of the UspAI outer membrane adhesin of Moraxella catarrhalis. Infect Immun 2005, 73( I 2):8247-8255.

6. Easton DM, Maier E, Benz R, Foxwell AR, Cripps AW, Kyd JM: Moraxella catarrhalis $\mathrm{M} 35$ is a general porin that is important for growth under nutrient-limiting conditions and in the nasopharynges of mice. J Bacteriol 2008, I90(24):7994-8002. 
7. Holm MM, Vanlerberg SL, Foley IM, Sledjeski DD, Lafontaine ER: The Moraxella catarrhalis Porin-Like Outer Membrane Protein CD Is an Adhesin for Human Lung Cells. Infection and Immunity 2004, 72(4): 1906-1913.

8. Rolhion N, Carvalho FA, Darfeuille-Michaud A: OmpC and the sigma(E) regulatory pathway are involved in adhesion and invasion of the Crohn's disease-associated Escherichia coli strain LF82. Mol Microbiol 2007, 63(6): 1684-1700.

9. Kim KS, Rao NN, Fraley CD, Kornberg A: Inorganic polyphosphate is essential for long-term survival and virulence factors in Shigella and Salmonella spp. Proceedings of the National Academy of Sciences 2002: I I2210499.

10. Bernardini ML, Sanna MG, Fontaine A, Sansonetti PJ: OmpC is involved in invasion of epithelial cells by Shigella flexneri. Infect Immun I 993, 6I(9):3625-3635.

II. Achouak W, Heulin T, Pages JM: Multiple facets of bacterial porins. FEMS Microbiol Lett 200I, I 99(I): I-7.

12. Tancharoen S, Matsuyama T, Abeyama K, Matsushita K, Kawahara K, Sangalungkarn V, Tokuda M, Hashiguchi T, Maruyama I, Izumi Y: The role of water channel aquaporin 3 in the mechanism of TNFalpha-mediated proinflammatory events: Implication in periodontal inflammation. J Cell Physiol 2008, 21 7(2):338-349.

13. Galdiero M, Vitiello M, Galdiero S: Eukaryotic cell signaling and transcriptional activation induced by bacterial porins. FEMS Microbiol Lett 2003, 226(I):57-64.

14. Galdiero M, D'Isanto M, Vitiello M, Finamore E, Peluso L: Porins from Salmonella enterica serovar Typhimurium induce TNF-alpha, IL-6 and IL-8 release by CDI4-independent and CDIIa/CDI8-dependent mechanisms. Microbiology 200I, | 47(Pt | 0):2697-2704.

15. Galdiero M, Finamore E, Rossano F, Gambuzza M, Catania MR, Teti G, Midiri A, Mancuso G: Haemophilus influenzae porin induces Toll-like receptor 2-mediated cytokine production in human monocytes and mouse macrophages. Infect Immun 2004, 72(2): I204-I 209

16. Massari P, Visintin A, Gunawardana J, Halmen KA, King CA, Golenbock DT, Wetzler LM: Meningococcal porin PorB binds to TLR2 and requires TLRI for signaling. J Immunol 2006, I 76(4):2373-2380.

17. Vitiello M, D'Isanto M, Galdiero M, Raieta K, Tortora A, Rotondo P Peluso L: Interleukin-8 production by THP-I cells stimulated by Salmonella enterica serovar Typhimurium porins is mediated by AP-I, NF-kappaB and MAPK pathways. Cytokine 2004, 27(I): $15-24$

18. Davin-Regli A, Bolla JM, James CE, Lavigne JP, Chevalier J, Garnotel E, Molitor A, Pages JM: Membrane permeability and regulation of drug "influx and efflux" in enterobacterial pathogens. Curr Drug Targets 2008, 9(9):750-759.

19. Delcour AH: Solute uptake through general porins. Front Biosci 2003, 8:d I055-I07I.

20. Nikaido H: Molecular basis of bacterial outer membrane permeability revisited. Microbiol Mol Biol Rev 2003, 67(4):593-656.

21. Schulz GE: The structure of bacterial outer membrane proteins. Biochim Biophys Acta 2002, I565(2):308-3I7.

22. Delcour $\mathrm{AH}$ : Outer membrane permeability and antibiotic resistance. Biochim Biophys Acta 2009, 1794(5):808-8I6.

23. Pages JM: [Bacterial porin and antibiotic susceptibility]. Med Sci (Paris) 2004, 20(3):346-35।.

24. Nikaido $\mathrm{H}$ : Outer membrane barrier as a mechanism of antimicrobial resistance. Antimicrob Agents Chemother 1989, 33(II): $183 \mid-1836$.

25. Danelon C, Nestorovich EM, Winterhalter M, Ceccarelli M, Bezrukov SM: Interaction of zwitterionic penicillins with the OmpF channel facilitates their translocation. Biophys J 2006 90(5):1617-1627.

26. Nestorovich EM, Danelon C, Winterhalter M, Bezrukov SM: Designed to penetrate: time-resolved interaction of single antibiotic molecules with bacterial pores. Proc Natl Acad Sci USA 2002, 99(15):9789-9794

27. Gotoh N, Tanaka S, Nishino T: Permeability of the outer membrane of Moraxella catarrhalis for beta-lactam antibiotics. J Antimicrob Chemother 1992, 29(3):279-285.

28. Easton DMSA, Gallego SG, Foxwell AR, Cripps AW, Kyd JM: Characterization of a novel porin protein from Moraxella catarrhalis and identification of an immunodominant surface loop. 2005, 187:6528-6535.
29. Wirth T, Morelli G, Kusecek B, van Belkum A, Schee $C$ van der, Meyer A, Achtman M: The rise and spread of a new pathogen: seroresistant Moraxella catarrhalis. Genome Res 2007, I7(I I): I647-I656.

30. Aebi C, Stone B, Beucher M, Cope LD, Maciver I, Thomas SE, McCracken GH Jr, Sparling PF, Hansen EJ: Expression of the CopB outer membrane protein by Moraxella catarrhalis is regulated by iron and affects iron acquisition from transferrin and lactoferrin. Infection and Immunity 1996, 64:2024-2030.

31. Hanahan D: Studies on transformation of Escherichia coli with plasmids. 1983, 166:557-580.

32. Helminen ME, Maciver I, Latimer JL, Lumbley SL, Cope LD, McCracken GH Jr: A mutation affecting expression of a major outer membrane protein of Moraxella catarrhalis alters serum resistance and survival of this organism in vivo. 1993 , 168:|194-I201.

33. Murphy TF, Loeb MR: Isolation of the outer membrane of Branhamella catarrhalis. 1989, 6:159-174.

34. Schaller A, Troller R, Molina D, Gallati S, Aebi C, Stutzmann Meier P: Rapid typing of Moraxella catarrhalis subpopulations based on outer membrane proteins using mass spectrometry. Proteomics 2006, 6(I): I72-180.

35. Meier PS, Troller R, Heiniger N, Grivea IN, Syrogiannopoulos GA Aebi $C$ : Moraxella catarrhalis strains with reduced expression of the UspA outer membrane proteins belong to a distinct subpopulation. Vaccine 2005, 23(16):2000-2008.

36. Spaniol V, Heiniger N, Troller R, Aebi C: Outer membrane protein UspAI and lipooligosaccharide are involved in invasion of human epithelial cells by Moraxella catarrhalis. Microbes Infect 2008, I O(I):3-II.

37. Aebi C, Lafontaine ER, Cope LD, Latimer LL, Lumbley SL, McCracken GH Jr, Hansen EJ: Phenotypic effect of isogenic uspAl and uspA2 mutations on Moraxella catarrhalis O35E. Infection and Immunity 1998, 66:31|3-3119.

38. Fink JML, Stewart GA, Graham PT, Steer JH, Joyce DA, McWilliam AS: Moraxella catarrhalis stimulates the release of proinflammatory cytokines and prostaglandin E from human respiratory epithelial cells and monocyte-derived macrophages. 2006, 46(2): 198-208.

39. Kaeriyama M, Machida K, Kitakaze A, Wang H, Lao Q, Fukamachi T, Saito $\mathrm{H}$, Kobayashi $\mathrm{H}$ : OmpC and OmpF are required for growth under hyperosmotic stress above pH 8 in Escherichia coli. Lett Appl Microbiol 2006, 42(3): 195-20I.

40. Massari $P$, Ram S, Macleod H, Wetzler LM: The role of porins in neisserial pathogenesis and immunity. Trends Microbiol 2003 I I (2):87-93.

4I. Thomas $A D$, Booth IR: The regulation of expression of the porin gene ompC by acid pH. I Gen Microbiol 1992, 138(9): I829-। 835 .

42. Stutzmann Meier P, Entenza JM, Vaudaux P, Francioli P, Glauser MP, Moreillon P: Study of Staphylococcus aureus Pathogenic Genes by Transfer and Expression in the Less Virulent Organism Streptococcus gordonii. Infection and Immunity 200I, 69(2):657.

43. Stutzmann Meier P, Heiniger N, Troller R, Aebi C: Salivary antibodies directed against outer membrane proteins of Moraxella catarrhalis in healthy adults. Infect Immun 2003, 7I(I 2):6793-6798

44. Murphy TF, Brauer AL, Aebi C, Sethi S: Identification of surface antigens of Moraxella catarrhalis as targets of human serum antibody responses in chronic obstructive pulmonary disease. Infect Immun 2005, 73(6):347I-3478.

45. Adlowitz DG, Kirkham C, Sethi S, Murphy TF: Human serum and mucosal antibody responses to outer membrane protein GIb of Moraxella catarrhalis in chronic obstructive pulmonary disease. FEMS Immunol Med Microbiol 2006, 46(I): I39-146.

46. Pearson MM, Lafontaine ER, Wagner NJ, Geme JW Jr, Hansen EJ: A hag Mutant of Moraxella catarrhalis Strain O35E Is Deficient in Hemagglutination, Autoagglutination, and Immunoglobulin D-Binding Activities. Infection and Immunity 2002 70(8):4523-4533

47. Hol C, Verduin CM, van Dijke E, VerhoefJ, Fleer A, van Dijk H: Complement resistance is a virulence factor of Branhamella (Moraxella) catarrhalis. 1995, I I:207-2I2

48. Brandtzaeg P, Halstensen TS: Immunology and immunopathology of tonsils. 1992, 47:64-75. 
49. Murphy S, Fitzgerald M, Mulcahy R, Keane C, Coakley D, Scott T: Studies on heamagglutination and serum resistance status of strains of Moraxella catarrhalis isolated from the elderly. Gerontology 1997, 43:277-282.

50. Attia AS, Lafontaine ER, Latimer JL, Aebi C, Syrogiannopoulos GA, Hansen Ej: The UspA2 protein of Moraxella catarrhalis is directly involved in the expression of serum resistance. Infect Immun 2005, 73(4):2400-24I0.

5I. Nordstrom T, Blom AM, Forsgren A, Riesbeck K: The emerging pathogen Moraxella catarrhalis interacts with complement inhibitor C4b binding protein through ubiquitous surface proteins AI and A2. Journal of Immunology 2004, 1 73(7):4598-4606.

52. Nordstrom T, Blom AM, Forsgren A, Riesbeck K: A novel interaction of C4b-binding protein (C4BP) with ubiquitous surface proteins AI and A2 (UspAI and A2) of Moraxella catarrhalis. Molecular Immunology 2004, 4 I (2-3):286.

53. Campagnari AA, Ducey TF, Rebmann CA: Outer membrane protein $\mathrm{BI}$, an iron-repressible protein conserved in the outer membrane of Moraxella (Branhamella) catarrhalis, binds human transferrin. Infection and Immunity 1996, 64(9):3920-3924.

54. Campagnari AA, Shanks KL, Dyer DW: Growth of Moraxella catarrhalis with human transferrin and lactoferrin: expression of iron-repressible proteins without siderophore production. Infect Immun 1994, 62(1 I):4909-49I4.

55. Furano $\mathrm{K}$, Campagnari AA: Inactivation of the Moraxella catarrhalis 7169 Ferric Uptake Regulator Increases Susceptibility to the Bactericidal Activity of Normal Human Sera. Infection and Immunity 2003, 7 I (4): I 843-I848.

56. Luke NR, Campagnari AA: Construction and characterization of Moraxella catarrhalis mutants defective in expression of transferrin receptors. Infection and Immunity 1999, 67:58I5-58I9.

57. Schryvers $A B$, Bonnah R, Yu RH, Wong $H$, Retzer M: Bacterial lactoferrin receptors. Adv Exp Med Biol 1998, 443:123-133.

58. Stojiljkovic I, Larson J, Hwa V, Anic S, So M: HmbR outer membrane receptors of pathogenic Neisseria spp.: iron-regulated, hemoglobin-binding proteins with a high level of primary structure conservation. J Bacteriol 1996, I 78( I 5):4670-4678

59. Furano $\mathrm{K}, \mathrm{NR}$ L, AJ H, AA C: Identification of a conserved Moraxella catarrhalis haemoglobin-utilization protein, MhuA. Microbiology 2005, I 5 I(Pt4): I I5I-I I58.

60. Slevogt H, Seybold J, Tiwari KN, Hocke AC, Jonatat C, Dietel S, Hippenstiel S, Singer BB, Bachmann S, Suttorp N, et al.: Moraxella catarrhalis is internalized in respiratory epithelial cells by a trigger-like mechanism and initiates a TLR2- and partly NODI-dependent inflammatory immune response. Cell Microbiol 2007, 9(3):694-707.

61. Lafontaine ER, Cope LD, Aebi C, Latimer JL, McCracken GH Jr, Hansen E): The UspAl protein and a second type of UspA2 protein mediate adherence of Moraxella catarrhalis to human epithelial cells in vitro. J Bacteriol 2000, I 82(5): I 364-I373.

62. Verduin CM, Hol C, Fleer A, van Dijk H, van Belkum A: Moraxella catarrhalis: from emerging to established pathogen. Clin Microbiol Rev 2002, I 5(I): I25-I44.

63. Harrison CJ, Woods C, Stout G, Martin B, Selvarangan R: Susceptibilities of Haemophilus influenzae, Streptococcus pneumoniae, including serotype 19A, and Moraxella catarrhalis paediatric isolates from 2005 to 2007 to commonly used antibiotics. J Antimicrob Chemother 2009, 63(3):5 I I-519.

64. Dagan R, Leibovitz E: Bacterial eradication in the treatment of otitis media. Lancet Infect Dis 2002, 2(10):593-604.

65. Helminen ME, Maciver I, Latimer JL, Cope LD, McCracken GH Jr, Hansen EJ: A major outer membrane protein of Moraxella catarrhalis is a target for antibodies that enhance pulmonary clearance of the pathogen in an animal model. Infection and Immunity 1993, 61:2003-2010.

66. Sambrook J, Fritsch E, Maniatis T: Molecular Cloning A Laboratory Manual. Second edition. Cold Spring Harbor, NY: Cold Spring Harbor Laboratory Press; 1989.

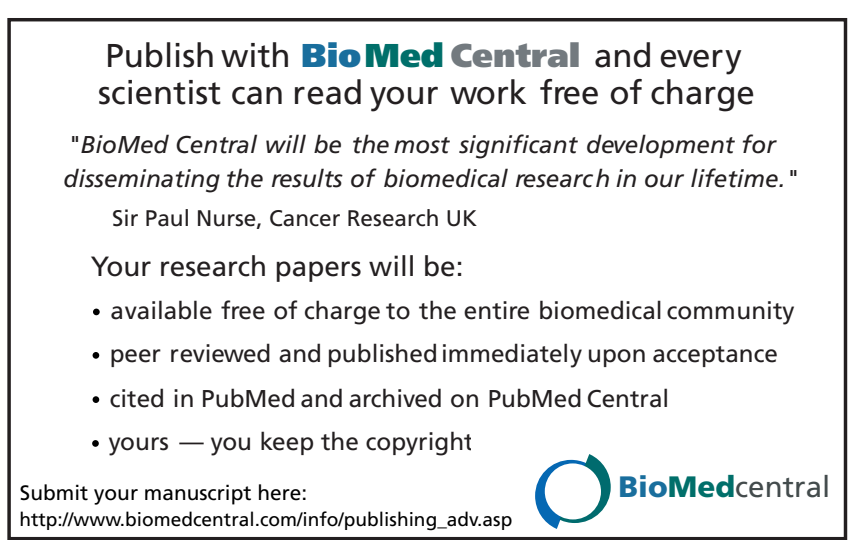

